\title{
La opacidad en los acuerdos globales. Una aproximación sociojurídica acerca del secreto en el campo legal
}

Opacity in Global Agreements. A Socio-Legal Approach about Secrecy in the Legal Field

Opacité dans les accords internationaux. Une approche sociojuridique à propos du secret sur

le plan juridique

\section{Carolina Filippon}

\section{OpenEdition} Journals

Edición electrónica

URL: http://journals.openedition.org/rccs/8989

DOI: $10.4000 /$ rccs.8989

ISSN: 2182-7435

Editor

Centro de Estudos Sociais da Universidade de Coimbra

\section{Edición impresa}

Fecha de publicación: 1 septiembre 2019

Paginación: 29-50

ISSN: 0254-1106

\section{Referencia electrónica}

Carolina Filippon, «La opacidad en los acuerdos globales. Una aproximación sociojurídica acerca del secreto en el campo legal », Revista Crítica de Ciências Sociais [En línea], 119 | 2019, Puesto en línea el 06 agosto 2019, consultado el 08 agosto 2019. URL : http://journals.openedition.org/rccs/8989 ; DOI : $10.4000 /$ rccs. 8989 


\section{CAROLINA FILIPPON}

\section{La opacidad en los acuerdos globales. Una aproximación sociojurídica acerca del secreto en el campo legal}

En el campo de los regímenes globales privados, los arreglos y prácticas entre los actores del sector privado transnacional y el Estado hacen gala un nivel de opacidad que ha obstaculizado el ejercicio de derechos fundamentales, tales como el acceso a la información pública. Consideramos fundamental estudiar esta tensión entre los regímenes globales privados y el campo de los derechos humanos, a través del estudio de las variables institucionales y legales del secreto, para poner de manifiesto el carácter funcional de la opacidad del derecho y de los procesos de publicización que permitieron la redefinición en el campo legal como un problema público.

Palabras-clave: acceso a la información; contratos internacionales; derecho a la información; derechos humanos.

Palavras-chave: acesso à informação; contratos internacionais; direito à informação; direitos humanos.

\section{Introducción}

En el campo de las ciencias sociales, el estudio del secreto no es reciente, en especial para los estudios sociológicos (Calhoun, 1992; Giraud, 2005; Simmel, 2014); sin embargo, no ha tenido la misma atención en el campo legal, ${ }^{1}$ donde tampoco se ha problematizado el diseño institucional y legal que garantiza el no acceso a la información (Pfersmann, 2006: 115). A este respecto, en este trabajo privilegiaremos una mirada sociojurídica crítica del campo legal.

\footnotetext{
${ }^{1}$ Utilizaremos la expresión "campo legal", acuñada por Pierre Bourdieu, en atención a que ésta integra nuestro marco teórico de referencia. Para Bourdieu en un campo "los agentes y las instituciones luchan permanentemente por apropiarse de productos específicos que se encuentran en disputa de acuerdo con las regularidades y las reglas constitutivas de este espacio de juego (y en ocasiones sobre las mismas reglas del juego) con distintos 'niveles de fuerza' entre los competidores y, por tanto, con muy diversas probabilidades de éxito" (Bourdieu y Teubner, 2000: 62).
} 
Un rasgo común de los ordenamientos jurídicos en el nuevo orden global está vinculado a las obligaciones de garantizar el acceso a la información que, por un lado, son puestas en cabeza de los Estados, por regímenes jurídicos nacionales e internacionales (tales como el derecho internacional público y el derecho internacional de los derechos humanos, entre muchos otros) y por otro, resultan desvirtuadas en los acuerdos que el mismo Estado celebra con empresas transnacionales.

En este sentido, el vínculo de los Estados con las empresas transnacionales, por ejemplo, bajo el paraguas de los tratados de inversión, está fuertemente vertebrado por normas jurídicas que garantizan el secreto de los acuerdos. En estos acuerdos el secretismo, lejos de ser una práctica aislada, resulta habitual y observable en un sinnúmero de casos pertenecientes a campos legales. Sin lugar a dudas, analizar la opacidad de estos acuerdos podría revelar algunas características del tipo de vínculo trabado entre los sujetos del corporativismo transnacional y el Estado.

Este artículo pretende poner de manifiesto la dimensión legal del secreto en la interface de campos legales, para luego indagar de qué modo la estructura legal de la opacidad del derecho le da una matriz a las relaciones del Estado con los actores del sector privado transnacional (SPT). Desde este ángulo, es posible advertir que los diferentes subsistemas legales estructuran y resguardan las relaciones jurídicas de modo que garanticen el no acceso a la información, impidiendo el ejercicio de otros derechos fundamentales.

Para desarrollar estos objetivos, el artículo presenta un estudio de caso centrado en el acuerdo secreto entre YPF -empresa de bandera nacional argentina- y Chevron -corporación multinacional- para la explotación de recursos naturales estratégicos, precedido por una cronología que permita ordenar temporalmente las complejidades del caso. En nuestra aproximación optaremos por presentar algunas experiencias de secretismo en el campo legal, para luego analizar el caso referido que, según nuestro criterio, pone en evidencia la dimensión institucional y legal del secreto, estando el Estado implicado en estas prácticas. Para ello, describiremos el marco legal que regula las relaciones entre el SPT y el Estado, en contraste con el que establece los derechos de acceso a la información.

Atendiendo a la especificidad que subyace en los casos de vinculación entre el Estado y los actores del SPT, partimos de las siguientes hipótesis: a) la opacidad del derecho es funcional a las relaciones jurídicas globales y b) la misma produce tensión entre el campo legal de los regímenes globales privados (RGP) y el de los derechos humanos (DD. HH.), que depositan en el Estado mandatos de regulación contradictorios de liberalización y protección. A nuestro juicio, esta tensión podría ser zanjada por el uso 
expansivo de dispositivos de DD. HH. a través de los cuales se operan procesos de publicización.

A la luz del estudio de caso, observaremos dentro del campo legal una inflexión en la institucionalización del secreto, surgiendo así la inquietud por determinar qué factores contribuyeron a ello.

\section{Experiencias de secretismo}

La construcción de la dimensión legal del secreto no ha sido lineal y esto ha quedado demostrado por la distinción temporal en el manejo del secreto por el Estado -trazada por Simmel. En los siglos XVII y XVIII los gobiernos mantenían en el más escrupuloso secreto el importe de las deudas del Estado, la situación de los impuestos, el número de soldados. Pero en el siglo XIX la publicidad se impone en los asuntos del Estado, hasta tal punto que los propios gobiernos publican oficialmente los datos que hasta entonces todo régimen debía mantener secretos si quería sostenerse (Simmel, 2014:392).

El siglo XIX representó un cambio paradigmático en cuanto a la incipiente exigencia de transparencia (Han, 2013: 82). La discreción y reserva quedaron circunscritas a la órbita privada, para ser reformuladas sólo en aquellos aspectos relacionados con asuntos públicos.

El caso de las agencias de inteligencia del Estado ilustra cabalmente la institucionalización de estructuras estatales inaccesibles al control democrático, utilizadas con fines de espionaje interno y con un manejo discrecional de fondos reservados, exentos de la rendición de cuentas. Los argumentos con los cuales se ha justificado esta suerte de inmunidad de la que gozan estos sectores del Estado, apuntan a la trascendencia de la política de seguridad nacional y reafirman falazmente que i) para lograr mayores niveles de seguridad son necesarios "elevados niveles de secreto", por lo que ii) un mayor acceso a la información pública podría traducirse en menor seguridad para la ciudadanía (Saba, 2017: 101). Se trata del "lado más oscuro y opaco del Estado" (Asociación por los Derechos Civiles, 2015: 2), y al mismo tiempo de una dimensión institucional del secreto.

La crisis relacionada con la agencia de inteligencia argentina desde finales del 2014, ${ }^{2}$ es un claro ejemplo de la publicización y consiguiente politización

\footnotetext{
${ }^{2} \mathrm{Al}$ respecto, debe recordarse que a finales del 2014 se publicizaron conflictos internos de la Secretaría de Inteligencia argentina (actualmente denominada Agencia Federal de Inteligencia), íntimamente relacionados con la muerte sorpresiva del Fiscal Federal A. Nisman, a cargo de la causa AMIA, el 18 de enero del 2015, un día antes de que el fiscal acudiera a declarar ante el Congreso Nacional por una denuncia que involucraba a las más altas esferas del poder. La excesiva autonomía de los sistemas de inteligencia ha llevado a la coexistencia de agentes estatales y paraestatales, y al manejo discrecional de fondos del Estado (Asociación por los Derechos Civiles, 2015).
} 
de estas estructuras, bajo cuya retórica se presentó la oportunidad de realizar reformas significativas orientadas a profesionalizar su estructura, hacerla transparente y sometida al control democrático. Sin embargo, la modificación del régimen legal de la Secretaría de Inteligencia en 2015 no previó los mecanismos que permitirían el acceso a la información pública, ni le otorgó una estructura institucional más transparente (Ley 27.126). ${ }^{3}$ La crisis no fue sino un proceso de redefinición de esta cuestión como un "problema", otrora regido por lógicas de secretismo, cuyo efecto inmediato fue su expropiación transitoria por actores de la arena pública. ${ }^{4}$ Desafortunadamente, a pesar de esta expropiación, no fue redefinido en términos de ampliación de derechos de acceso a la información pública ni de un diseño institucional más transparente.

Este conjunto de prácticas enunciadas a modo de casos constituye una muestra significativa, dado que incluye la participación del Estado. En contraste con este repertorio de ejemplos de prácticas opacas que involucran al Estado, ha sido el mismo Estado el que ha reforzado la caja de herramientas tendientes a garantizar la accesibilidad, a través de reformas legales y judiciales. En este sentido se puede leer, por ejemplo, la sanción de la Ley de Acceso a la Información Pública 27.275/16, ${ }^{5}$ cuya racionalidad es claramente publicista.

Esta nueva norma destaca por prever una legitimación pasiva, acentuadamente amplia, pero también por establecer que las excepciones "[...] no serán aplicables en casos de graves violaciones de derechos bumanos [...]" (art. 8; itálico añadido). Esta disposición, de prosa clara y concluyente, abre una ventana en los casos donde la protección de intereses privados -mediante la invocación de la protección de secretos industriales, comerciales o científicos- tiende a bloquear el acceso a información, violando los DD. HH. Está claro que esta norma resultará pertinente para el caso de estudio escogido, ya que entre los argumentos esgrimidos por YPF (parte demandada) para no hacer público el contrato con Chevron se hallaba la apelación a la protección del secreto industrial.

\footnotetext{
${ }^{3}$ Esta ley creó la Agencia Federal de Inteligencia argentina. Véase el capítulo 3 "De la información, archivos de inteligencia y desclasificación”.

${ }^{4} \mathrm{Al}$ respecto, Gilbert y Henry han señalado que "los procesos de definición que les dan a los problemas características determinando sus condiciones de existencia resultan pues, en primer lugar, de lógicas sociales que no son siempre consideradas como referencias de arenas de debate público. Muy por el contrario, estos procesos son regidos generalmente por lógicas de compromiso o de confinamiento, que caracterizan las modalidades rutinarias de apropiación de problemas por los actores a cargo de éstos" (2012: 51; traducción propia).

${ }_{5}^{5}$ Ley 27.275/16 "Acceso a la Información Pública”, 14 de septiembre de 2016. Buenos Aires, Argentina: Ministerio de Justicia y Derechos Humanos.
} 
Sin embargo, esto no solo se debe al marco legal, sino también a la jurisprudencia que ha reforzado los mecanismos orientados a garantizar la publicización de la información. En esta línea se sitúa el reconocimiento del derecho de acceso a la información, tanto por parte de varios tribunales inferiores argentinos como por la Corte Suprema de Justicia de la Nación (CSJN). Entre estos casos, no se puede dejar de mencionar la sentencia de la CSJN "Cippec c/ EN-Ministerio de Desarrollo Social, Decreto 1172/03 s/ amparo Ley 16.086”, en cuyo precedente se afirmó de modo categórico que "la información no pertenece al Estado, sino que es del pueblo de la Nación Argentina" (Considerando ${ }^{6}$ 12, 2. ${ }^{\circ}$ párr.).

\section{Las prácticas legales bajo un velo de opacidad}

Las consideraciones efectuadas anteriormente con relación a experiencias de secretismo en Argentina, permiten señalar que ya han habido procesos de definición de materias y de casos sujetos a secreto en algunos campos legales, como los vinculados al funcionamiento de la agencia de inteligencia del Estado. Las referencias realizadas ut supra ponen de manifiesto la construcción de la dimensión legal del secreto.

Es factible complementar esas consideraciones empíricas con los aportes teóricos. En este sentido, en el plano teórico las problemáticas del secreto, de la opacidad del derecho como del acceso a la información, han sido objeto de atención de los estudios sociológicos (Gilbert y Henry, 2012; Simmel, 2014) y sociojurídicos (Cárcova, 1998; Pfersmann, 2006; Abramovich, 2015; Saba, 2017).

Interesa aquí resaltar el concepto de Simmel (2014: 378), que compartimos, sobre el secreto como ocultación deliberada, una técnica sociológica que se mantiene neutral con independencia del contenido; una forma de acción sin la cual ciertos fines no podrían ser alcanzados. Este sociólogo alemán explica que la finalidad del secreto es, ante todo, la protección, siendo las "sociedades secretas" una medida radical de protección, una forma social en la que se refugian las sociedades ascendentes y decadentes.

Asimismo, es significativo recuperar la dimensión institucional del secreto atendiendo a los aportes que la teoría social y los estudios sociojurídicos han producido sobre los procesos de globalización del derecho y el pluralismo jurídico. Esta dimensión coadyuvará a entender que existe una trama de relaciones jurídicas de las que forma parte el Estado y que obedecen a una racionalidad de discreción y secretismo, marcadas por la especificidad de la arena en la que se gestan acuerdos globales (comerciales, financieros, etc.).

${ }^{6}$ En adelante Cons. 
Los estudios sociojurídicos han abordado esta dimensión institucional, máxime los estudios críticos del derecho, cuyo enfoque crítico entiende al derecho como una práctica social compleja. Bajo esta luz, la institucionalización de la opacidad no es casual, sino funcional en una lógica -de desregulación, liberalización, flexibilización- del campo legal transnacional. $\mathrm{Al}$ respecto, Cárcova sostiene que:

El poder asentado en el conocimiento del modo de operar del derecho se ejerce, parcialmente, a través del desconocimiento generalizado de esos modos de operar. La preservación de ese poder resulta, así, fatalmente enlazada con la reproducción del efecto del desconocimiento. De ello se sigue que la opacidad del derecho, su intransparencia, $[\ldots]$ lejos de ser un accidente o acaso un problema instrumental susceptible de resolverse mediante oportunas reformas, se perfila como una demanda objetiva de funcionamiento del sistema. (Cárcova, 1998: 160)

Los términos de los acuerdos entre el Estado y las empresas transnacionales (ETs) oscilan entre reglas de confidencialidad y de publicización, con la consiguiente habilitación de mecanismos legales de acceso a la información. Sin embargo, es necesario trazar algunas distinciones.

En primer lugar, poner nuestro foco de análisis en la accesibilidad o no de la información representa solo uno de los ángulos posibles y su elección excluye cuestiones de igual o incluso de mayor trascendencia. Así, por ejemplo, definir los acuerdos comerciales de un Estado con empresas de capitales internacionales (overlapping authorities) ${ }^{7}$ como un asunto privado (Sassen, 2010: 253-254), relega la participación de una cantidad atendible de actores. ${ }^{8}$

En segundo lugar, la definición del carácter público o confidencial de la información es acompañada por el diseño de reglas legales e institucionales. En general, la categorización de un problema o cuestión como "no accesible" apela a criterios de dominios técnicos - científico, administrativo, jurídico- (Gilbert y Henry, 2012: 42). Esto es lo que sucede en el ámbito de la contratación internacional, cuyo nivel de tecnicidad es muy alto. El conocimiento experto en estas órbitas bloquea el acceso de la comunidad no solo a la discusión de un sinfín de problemáticas, sino al conocimiento

\footnotetext{
${ }_{7}$ Muir Watt (2016: 5) señala que durante el último período de tiempo un rico corpus teórico del derecho internacional estableció al pluralismo jurídico como un arco teórico útil para comprender un mundo de superposiciones relativas de autoridades, tanto estatales como no estatales.

${ }^{8}$ No podemos dejar de llamar la atención sobre la reconfiguración de la noción de autoridad (en lo que refiere a la producción de legalidad e institucionalidad) y de interés público. Al respecto, Sassen ha analizado esta transformación advirtiendo que las formas de autoridad, otrora emplazadas exclusivamente en la esfera pública, han comenzado a constituirse en la esfera privada de los mercados, con la consiguiente reconfiguración de los sistemas jurídicos.
} 
de su propia existencia. De modo que a través de prácticas del derecho se crean distinciones entre lo público y lo confidencial, que luego pasan a ser institucionalizadas. Las primeras son las que consagran el carácter público, previendo también su acceso. Es decir, contemplan el derecho de acceso a la información pública. ${ }^{9}$ Desde una perspectiva legal, la referencia a los DD. HH. se hace en estricta alusión al derecho humano de acceso a la información pública, que ha sido regulado tanto en el campo legal nacional como en el plano internacional. El derecho de acceso a la información se ha institucionalizado como un derecho humano porque es funcional para el ejercicio del vasto conjunto de los restantes DD. HH. Para el desarrollo de esta investigación, la trascendencia de este derecho radica en tornar asequible el proceso de publicización, junto con la juridificación del conflicto. Gilbert y Henry (2012) formularon una tesis que compartimos, según la cual el estudio de los problemas públicos -y de sus mecanismos de definición- se centra en espacios de debate público y/o en procesos de publicización, en los que diferentes dispositivos -mediáticos, jurídicos y/u otros registros de acción colectiva- procuran ampliar la participación del público interesado -real o potencial. Entre estos dispositivos se halla el derecho humano de acceso a la información pública, cuyo empleo en el caso de estudio ha conducido a un proceso de publicización. Los procesos de publicización son entendidos por estos autores como el desmadre consiguiente a un desacuerdo, un conflicto que no ha sido posible regular en el marco de un sistema de relaciones, y se traduce en la inscripción de esa cuestión en el espacio público (ibidem: 53). Indirectamente estos procesos coadyuvan a modificar las relaciones de fuerza entre actores, los tipos de discurso y posturas que en espacios confinados suelen ser invalidados, constituyéndose así en un recurso disponible para los actores sociales débiles. Sin embargo, no se debe soslayar que la categorización de los problemas como públicos puede suceder a) por un desacuerdo que no ha podido ser zanjado en el marco de un sistema de relaciones, inscribiéndose en el espacio público, o b) incluso en campos sujetos a lógicas de confinamiento (ibidem: 48), como los RGP. Esta tesis permite formular, preliminarmente, que la construcción del carácter público de una cuestión puede darse en espacios que responden a lógicas discrecionales.

El caso de los contratos entre el Estado y ETs con cláusulas secretas constituye un ejemplo de un campo sujeto a lógicas de confinamiento,

\footnotetext{
${ }^{9}$ Las normas legales dentro de las cuales se enmarca este derecho y que le dan contenido serán referidas en el apartado sobre el análisis del caso, en el cual se escrutará este derecho en su aspecto dinámico.
} 
dado que los principales compromisos que estructuran este vínculo son parte de un acuerdo incardinado en espacios altamente técnicos y privados, pero con directa incidencia en el ejercicio de derechos que emanan de otro régimen legal: el de los DD. $\mathrm{HH}$.

Al respecto, Teubner (2012: 124) sostiene que es sumamente difícil negar los efectos de los derechos fundamentales en áreas no estatales, contra actores privados transnacionales, atendiendo principalmente a la creciente cantidad de casos de violaciones de los derechos humanos por parte de empresas transnacionales que se han planteado ante tribunales nacionales e internacionales.

Asimismo, Ladeur y Viellechner (apud Teubner, 2012: 125) sostienen que la validez de los DD. HH. previstos por los Estados se extiende a los regímenes "privados" transnacionales -que aquí hemos denominado RGP_ por tres razones: a) la mayor permeabilidad del derecho nacional e internacional, b) la creación de redes de tribunales constitucionales nacionales y c) el aumento de la intercambiabilidad del derecho privado y público. Este último factor es esencial para el argumento que sostenemos aquí, por cuanto la tensión entre los RGP y el campo legal de los DD. HH. también puede ser explicada por la dicotomía entre lo público y lo privado. Esta tensión patente en el avance de los regímenes transnacionales sobre los DD. HH., puede ser contrarrestada a su paso por el uso expansivo de los DD. HH., que operativizan procesos de publicización.

La formulación de Gilbert y Henry sobre la publicización de cuestiones convenidas previamente como no accesibles, según nuestro criterio, admite ser desagregada en dos supuestos: a) son el resultado de la ruptura de acuerdos entre los actores involucrados, y/o b) de la tensión no resuelta entre espacios confinados y espacios públicos. Este último es el supuesto bajo el cual entendemos la publicización de contratos secretos que involucran al Estado. En otras palabras, la publicización de contratos secretos es el resultado de la tensión entre campos legales privados y campos legales públicos.

$\mathrm{Al}$ respecto, se ha señalado que existe una tensión -permanente o cuanto menos latente- entre lógicas propias de los espacios confinados y de arenas públicas, por lo que "es en función de esta tensión que se efectúa con frecuencia la definición de problemas, sabiendo que a cada problema corresponde su historia, su tipo de sistema de actores intervinientes de modo directo, así como su tipo de relación en las arenas públicas" (Gilbert y Henry, 2012: 54; traducción propia).

Esta tensión identificada por la teoría social fue denominada por los estudios sociojurídicos como legal overlapping, es decir, la coexistencia de modelos regulatorios suscriptos a racionalidades diversas y disímiles. 
Esto se puede observar con mayor claridad en el caso de los países latinoamericanos, que durante el período neoliberal de los años 90 del siglo XX incorporaron a sus Constituciones los tratados internacionales de DD. HH., ampliando de esta manera la carta de derechos, así como los mecanismos de participación democrática. Paradójicamente, estos mismos Estados se adhirieron simultáneamente a los RGP, es decir, al régimen de comercio internacional, de inversión extranjera o de mercado de capitales. Se trató de una inserción global en regímenes orientados a la desregulación económica, el fomento de la inversión privada transnacional y la precarización laboral, entre otros. En esta línea, la información ocultada y las técnicas legales para alejarla del acceso público constituyen una dimensión patrimonial y estructural para estos regímenes.

Dicho fenómeno de legal overlapping también es abordado en términos de pluralismo jurídico, ${ }^{10}$ en alusión a una multiplicidad de ordenamientos legales internacionales y a la coexistencia de "formas de derecho infraestatal, informal, no oficial y más o menos consuetudinario" (Santos, 2003: 234). Santos lo define como la yuxtaposición, articulación e interpenetración de varios espacios jurídicos, en el que el proceso de producción normativa excede el ámbito de los Estados. La referencia al pluralismo jurídico es forzosa por su carácter de marco dentro del cual operan los RGP, y en cuyo contexto instauran una constelación compleja de campos regulatorios que se caracterizan por un funcionamiento descentralizado y un fuerte grado de autonomía (Teubner, 2004; Muir Watt, 2016). El referido margen de autonomía explica que el contenido de los arreglos entre los actores del SPT y los Estados rehúya las reglas de control democrático, quedando oculto al acceso público.

Siguiendo a Teubner, los RGP se caracterizan por su dimensión despolitizadora, descentralizadora y de desindividualización, entendidos a su vez como procesos autónomos de globalización. "Cada vez más, los RGP están produciendo leyes sustantivas sin el Estado, sin legislación nacional ni tratados internacionales" (Teubner, 2004: 2; traducción propia). El despliegue de la autonomía de los actores privados y la expansión de la codificación privada, ha operado la descentralización de la producción normativa, hoy en día alejada de la facultad legisferante del Estado.

\footnotetext{
${ }^{10}$ Este término fue utilizado en referencia al reconocimiento de diferentes tradiciones y fuentes del derecho de un sistema jurídico. Asimismo, alude al estudio de las relaciones entre normas e instituciones regionales en escenarios locales, deteniéndose en el trasplante de institutos legales y las relaciones entre regímenes nacionales, locales y globales. Destacamos aquí que este fenómeno ha sido atendido prioritariamente por estudios del derecho internacional. Véase: Teubner (1998), Muir Watt (2011) y Berman (2012), entre otros.
} 
Aunque con notables excepciones, los RGP son indiferentes -parafraseando la obra de Santos- al impacto que ejercen sobre otros regímenes, como el de los DD. HH., para concentrarse en el diseño altamente técnico de normas. En este sentido, es un campo legal poco reflexivo. No se trata de un régimen, sino de numerosos regímenes legales internacionales circulando a la vez. Un "derecho poroso constituido por múltiples redes de órdenes jurídicos que nos fuerzan a constantes transiciones y transgresiones" (Santos, 2003: 251).

En esta misma línea, más allá las definiciones, la mayoría de los autores coincide en que el Estado ha perdido el control sobre los procesos de producción de la legalidad. El derecho se produce dentro del espacio estatal y en los márgenes de los regímenes políticos constitucionales, por actores globales no estatales. "La ampliación de mandatos regulatorios [sobre el Estado] para tutelar derechos entra en tensión con los mandatos 'desreguladores' que imponen los mencionados regímenes económicos internacionales, orientados a la protección de los mercados" (Abramovich, 2015: 11).

Por su parte, los conflictos vinculados al carácter opaco de la información pública ingresaron en la agenda del derecho reformulándolo estructuralmente, como se advierte en casos puntuales: conflictos en los servicios de inteligencia del Estado, laudos arbitrales internacionales y asociaciones público-privadas, entre otros. Aquí nos interesa detenernos sobre aquellos casos que han puesto en diálogo -y tensión- al régimen de los DD. HH. y al campo legal privatista internacional.

En la interface de estos, los RGP presentan mayor nivel de hermetismo ante herramientas que tienden a abrir rutas de acceso a la información. Esto resulta notorio en el caso de estudio escogido. En este, la judicialización ocasionada por la inaccesibilidad de las cláusulas del contrato entre el Estado y la ETs no sólo constituye una variante de los procesos de juridificación de conflictos, ${ }^{11}$ sino también una estrategia de publicización, que lo expropia a los actores que convinieron la opacidad del acuerdo.

\section{El Convenio entre YPF y Chevron: el secreto como válvula de escape al control democrático}

Los casos de litigios por conflictos vinculados a la falta de acceso a información pública ambiental son estratégicos, porque intentan modificar las relaciones de poder que subyacen en los acuerdos público-privados.

\footnotetext{
${ }^{11}$ Se refiere al proceso social a través del cual "las expectativas normativas que se elaboran en el campo ambiental se convierten en normas jurídicas. [...] Se trata de establecer la conexión entre lo que dicen las leyes, los reglamentos, las sentencias de los jueces, etc., y las expectativas sociales que en un principio las motivaron" (Azuela, 2006: 55).
} 
El caso del convenio entre Chevron Corp. e YPF S.A. ${ }^{12}$ se incardina en esta línea.

Este convenio se firmó en el marco de una coyuntura de agotamiento de la matriz energética, aumento del consumo energético y caída constante de la extracción de gas y petróleo, en el cual Argentina decidió realizar reformas legales e institucionales para preparar el terreno para nuevas actividades extractivas.

En esa dirección, se adoptó una batería de medidas legales tendientes a preparar las condiciones de producción, que comprenden: a) la Ley $26.741 / 12^{13}$ que dispuso un régimen dirigido a declarar de interés público el logro del autoabastecimiento de hidrocarburos, y de utilidad pública la expropiación del $51 \%$ de la empresa YPF y Repsol YPF Gas S.A.; b) el Decreto $546 / 03,{ }^{14}$ que reconoció a las provincias el derecho de otorgar permisos de exploración y concesiones de explotación, y c) la Ley 26.197/06, ${ }^{15}$ que culminó con el proceso de transferencia del dominio de los recursos de la nación a las provincias.

Previamente, hacia finales de 2010, se había dado a conocer el potencial argentino en hidrocarburos de yacimientos no convencionales por el descubrimiento -anunciado por YPF- de una reserva de shale gas en Vaca Muerta, Neuquén (Kuuskraa et al., 2011). Los estudios exploratorios realizados alentaron fuertemente el interés de ETs en su explotación. Así expuesto el panorama, el potencial de estos yacimientos se presentaba como una salida tentadora frente a la crisis energética y como incentivo de otras actividades productivas.

En el plano legal, se dispuso la creación de un régimen de promoción de inversión para la explotación de hidrocarburos (Decreto 929/13) ${ }^{16}$ que, en sintonía con la Ley $26.741 / 12$, declaró de interés público nacional y como objetivo prioritario el logro del autoabastecimiento de hidrocarburos, su exploración, explotación e industrialización.

Toda esta batería de medidas legales indica que la misma no estaba destinada a revitalizar el control del Estado sobre sus recursos naturales y su ulterior explotación, sino a garantizar el acceso del SPT a los mismos,

\footnotetext{
${ }_{12}$ En adelante Chevron e YPF.

${ }^{13}$ Ley 26.741/12 "Soberanía Hidrocarburífera", 4 de mayo de 2012. Buenos Aires, Argentina: Ministerio de Justicia y Derechos Humanos.

${ }_{14}$ Decreto 546/03 "Explotación de Hidrocarburos", 6 de agosto de 2003. Buenos Aires, Argentina: Ministerio de Justicia y Derechos Humanos.

15 Ley 26.197/06 "Hidrocarburos", 6 de diciembre de 2006. Buenos Aires, Argentina: Ministerio de Justicia y Derechos Humanos.

16 Decreto 929/13 “Soberanía Hidrocarburífera", 11 de julio de 2013. Buenos Aires, Argentina: Ministerio de Justicia y Derechos Humanos.
} 
ya que el Estado acordó que dichos recursos sean explotados por este sector. En este sentido, estas concesiones integran un auténtico acuerdo pactado entre el Estado y el capital transnacional, opaco al acceso de la ciudadanía, y están acompañadas por un relajamiento de la fiscalización estatal.

\section{El Acuerdo YPF - Chevron}

La desinversión y el endeudamiento de la empresa de bandera nacional no dejaban más salida que vincularse con el sector privado. La cuestión era saber con quién asociarse y bajo qué condiciones (AAVV, 2014: 71).

Tras la expropiación parcial de YPF el camino para cerrar el convenio con Chevron estaba allanado; no obstante, el modelo no fue de estatización, sino que se mantuvo bajo el régimen de las sociedades comerciales como sociedad anónima (Casa Rosada, 2012). De este modo, en 2012 se desató la exploración de los no convencionales y la consiguiente expansión de la frontera hidrocarburífera.

El convenio fue precedido por una suerte de alineamiento entre el Estado argentino y la provincia interesada (Neuquén), cristalizado en la renovación del contrato entre esa provincia (asiento de la futura explotación) e YPF, avalando de este modo la vinculación entre YPF y Chevron. Así, se dio forma al consenso que el Estado nacional necesitaba para asociarse a la multinacional.

En agosto del año 2013, el Congreso de Neuquén aprobó el convenio entre YPF y Chevron a ciegas, desconociendo sus cláusulas, poniendo de manifiesto el secretismo que revestiría todo el caso.

Un día antes de la firma del convenio, se dictó el Decreto 929/13 de "Soberanía Hidrocarburífera" por el cual se establecía un régimen de promoción de inversión para la explotación de hidrocarburos, cuyas previsiones respondían a la perfección a las condiciones que el SPT impusiera para asociarse, consagrando cuantiosos beneficios impositivos, fiscales y comerciales. Aún con la previsión de todos estos beneficios, las cláusulas del convenio continuaron blindadas tanto al acceso público como a los controles fiscales, convirtiéndose en el elemento más sensible del acuerdo suscripto el 16 de julio de 2013. De modo que en este caso el secreto no tuvo que ver con la asociación en sí misma, sino con los términos del vínculo. No se trató de las "sociedades secretas" de Simmel (2014). Debe recordarse que para este "la técnica del secreto [...] no es meramente un medio [...] sino que muchas veces la asociación sirve para garantizar el secreto de determinados contenidos" (ibidem: 407).

Tras la firma del Acuerdo de Proyecto de Inversión, el entonces diputado provincial Rubén Giustiniani solicitó a YPF una copia íntegra del mismo 
fundándose en el Decreto 1172/03. ${ }^{17}$ La empresa respondió manifestando su negativa, ya que entendía que no se encontraba sujeta a las normas del decreto que prevén el acceso a la información pública del Poder Ejecutivo Nacional (PEN), excusándose en su forma societaria de derecho privado.

Ante esta negativa, el requerimiento de información fue reiterado, ampliando la solicitud sobre los impactos ambientales de dicho proyecto y la consulta a las comunidades originarias allí instaladas. Con todo, la falta de respuesta de YPF propició que se presentara un recurso de amparo por el acceso a la información pública y ambiental. La tentativa de mantener la opacidad del contrato dejó planteada la oportunidad para que el caso, finalmente, se judicializara.

Tras la resolución denegatoria de las dos primeras instancias judiciales, el caso llegó finalmente a la CSJN, que recuperó la jurisprudencia de la Corte Interamericana de Derechos Humanos (Corte IDH). Sobre esto, cabe recordar que la Corte IDH ha dado "un amplio contenido al derecho a la libertad de pensamiento y de expresión, a través de la descripción de sus dimensiones individual y social" (Cons. $6,1^{\circ}$ párr.), siendo que del artículo 13 de la Convención se desprende el derecho de acceso a la información, que consagra el derecho a la libertad de pensamiento y de expresión.

En segundo lugar, considerando las funciones asignadas legalmente y el rol que desempeña el PEN en su ejecución, sentenció que YPF “es uno de los sujetos que, por encontrarse bajo la jurisdicción del PEN, se halla obligado a dar cumplimiento a las disposiciones del Decreto 1172/03 en materia de información pública" (Cons. 13). ${ }^{18}$

Los considerandos del fallo "Giustiniani, Rubén H. c/ YPF S.A. s/ amparo por mora" (2015) permiten concluir que se recurrió a figuras legales del derecho privado - como las sociedades anónimas- con el propósito de sortear la aplicación de normas inherentes a la administración.

La ponderación efectuada por la CSJN no le dejó otra opción sino afirmar que YPF "no puede, en el marco de los principios de una sociedad democrática y de acuerdo a la jurisprudencia reseñada, negar información de indudable interés público, que hace a la transparencia y a la publicidad de su gestión" (Cons. 17). En este sentido, el Decreto 1172/03 se presenta como un dispositivo de control democrático (de racionalidad publicista),

\footnotetext{
${ }^{17}$ Decreto 1172/03 "Reglamento General del Acceso a la Información Pública para el Poder Ejecutivo Nacional”, 3 de diciembre de 2003. Buenos Aires: Ministerio de Justicia y Derechos Humanos.

${ }_{18} \mathrm{Al}$ respecto, la CSJN hizo referencia al artículo 2 del Anexo VII del Decreto 1172/03, invocado para exigir el acceso a la información.
} 
que conlleva implícito el derecho de toda la ciudadanía de acceder a la información pública, en atención a que no se corroboraron ninguna de las excepciones invocadas. ${ }^{19}$

Todo este análisis permitió que la CSJN concluyera que:

[...] el derecho de acceso a la información, en tanto elemento constitutivo de la libertad de expresión protegido por normas constitucionales y convencionales, no es un derecho absoluto sino que puede estar sujeto a limitaciones. No obstante ello, tales restricciones deben ser verdaderamente excepcionales, perseguir objetivos legítimos y ser necesarias para alcanzar la finalidad perseguida. En efecto, el secreto sólo puede justificarse para proteger un interés igualmente público, por lo tanto, la reserva solo resulta admisible para 'asegurar el respeto a los derechos o la reputación de los demás' o 'la protección de la seguridad nacional, el orden público o la salud o la moral públicas', citado (confr. Claude Reyes, citado). (Cons. 25)20

Paradójicamente, las alianzas del Estado con las corporaciones transnacionales lejos de ser inescrutables, en los términos de este razonamiento jurisprudencial, quedan sujetas a estos mecanismos de transparencia.

Con todo, la sentencia de la CSJN no fue suficiente para lograr que YPF diese a conocer el acuerdo. Antes de que se hiciera pública, trascendió que Chevron había diseñado una estructura orientada a resguardar su inversión productiva ante eventuales riesgos legales. La trama legal tejida a la medida de los intereses del SPT abarcó, entre otras estrategias, la creación de otras empresas y la celebración de otros 26 contratos. Una pantalla legal genuinamente enrevesada.

El 10 de octubre de 2016, YPF entregó una copia a la Justicia que fue remitida al entonces Senador Giustiniani (actor de la causa judicial), quien remitió copias al Congreso, a la Auditoría General de la Nación y a la Defensoría del Pueblo. El acceso al mismo permitió conocer que no se trató de un acuerdo de inversión, sino de un préstamo.

Incardinado en el plano de la accesibilidad a la información pública y con el aditamento de estar intersectando diferentes campos legales, este caso

\footnotetext{
${ }_{19}$ Las excepciones al acceso a la información pública son reguladas en el artículo 16 del Anexo VII del Decreto 1172/03, y al acceso a la información pública ambiental en el artículo 7, inciso $c$, de la Ley de Libre Acceso a la Información Pública Ambiental 25.831/04.

Entre las excepciones del Decreto 1172/03 se mencionan casos de información expresamente clasificada como reservada; información que comprometa derechos o intereses legítimos de un tercero obtenida en carácter confidencial; secretos industriales, comerciales, financieros, científicos; etc. Este último supuesto está previsto asimismo por el artículo 7, inciso $c$, de la Ley 25.831.

${ }^{20}$ Corte Suprema de Justicia de la Nación, 10 de noviembre de 2015, "Giustiniani, Rubén Héctor c/ Y.P.F. S.A. s/ amparo por mora”. Consultado el 11.07.2019, en https://bit.ly/2XHhKqt.
} 
hizo evidente que cuando el Estado actúa como sujeto privado en el proceso de lawmaking con actores globales, lo hace bajo un velo de discreción de mayor o menor opacidad.

La publicización condujo aquí a su ingreso en la agenda del Estado, inscribiéndose en un dominio: la vinculación del Estado con actores del SPT. Es posible, pues, concluir que este tipo de acuerdos, conjuntamente con la batería de leyes dispuesta por el Estado, restringe el control del mismo al delegar en actores privados las funciones de control y gestión de conflictos, y resguardando con "el secreto aspectos claves del proceso extractivo, lo que dificulta realizar mecanismos de consulta y facilita evadir el control político y social de los emprendimientos" (Abramovich, 2015: 18). ${ }^{21}$

El convenio puso al descubierto que un acuerdo secreto había devenido en un problema público: el del acceso a información pública. Esto plantea dos cuestiones: i) un proceso de construcción como problema público y ii) la tensión entre campos regulatorios que actúan sobre el mismo objeto: la accesibilidad a la información.

Dentro de esta aproximación, surge un interrogante sobre el proceso de definición que utiliza el derecho para distinguir la información pública de la inaccesible. Al respecto, para Gilbert y Henry los mecanismos de definición de los problemas en algunos casos responden a lógicas de publicización, mientras que en otros son definidos con criterios de discreción (2012: 38). En el caso bajo estudio, el régimen de los DD. HH. es el que concentra criterios de definición de lo público, operando su publicización.

Tanto para el derecho constitucional argentino como para el derecho ambiental, el acceso a la información pública representa un elemento clave para el ejercicio de otros derechos fundamentales, para proyectar un programa de desarrollo (Basterra, 2014: 132) y para prevenir la conculcación de derechos fundamentales de difícil o imposible reparación ulterior, tales como gestionar sistemas naturales y riesgos asociados a su explotación. Por todo ello, es obligación del Estado garantizar su ejercicio.

Por lo tanto, el acceso a la información se plantea como un derecho colectivo, constitucional, que descansa sobre un bien público y colectivo, con un marcado carácter social y sobre el que se asienta el control institucional (Abramovich y Courtis, 2000: 3). En contraste, la regulación que los RGP le deparan a la información refieren a un bien individual y privado.

Cualquiera que sea el mecanismo a través del cual se garantice el acceso, es ineludible la previa expropiación del problema hacia las arenas públicas.

${ }^{21}$ En el mismo sentido sobre el proceso de transferencia de funciones desde el Estado hacia actores privados, cf. Sassen (2012: 44). 
En este caso, el desafío al que se enfrentó el Estado consistió en asegurar la primacía de la lógica de publicización sobre la de confinamiento, en la intersección de campos legales.

Sin embargo, estas reglas están sujetas a restricciones cuando se pueda ver afectada la defensa nacional, las relaciones internacionales o cuando esta haya sido legalmente clasificada como secreta. Con esta misma lógica, la información que se encuentre sujeta a algún proceso judicial o que pueda afectar al secreto comercial, industrial, la propiedad intelectual o la confidencialidad de datos personales, también queda ajena al acceso público.

\section{Luchas por la redefinición de lo "secreto"}

Como hemos mencionamos, el campo legal presenta un abanico de experiencias que ponen de manifiesto la opacidad del derecho y la tensión entre subcampos con lógicas diversas. En el terreno del derecho privado, se blinda la información a través de cláusulas de confidencialidad bajo fórmulas de "secreto comercial, industrial", "seguridad nacional" y "defensa nacional", entre otras.

En contraste, los DD. HH. inocularon en el derecho público argentino una batería de dispositivos para operativizar el acceso que comprenden la Ley General del Ambiente 25.675,22 el Decreto 1172/03, la Ley 27.275/16 de Acceso a la Información Pública y el Régimen de Libre Acceso a la Información Ambiental Ley 25.831/04,23 amén de los instrumentos derivados de los tratados internacionales y la jurisprudencia constitucional ${ }^{24}$ e internacional. ${ }^{25}$ Esto no es más que un uso expansivo de los DD. HH., al que alude Teubner (2012: 124-139).

\footnotetext{
${ }^{22}$ Ley 25.675/02 "Política Ambiental Nacional", 6 de noviembre de 2002 . Buenos Aires, Argentina: Ministerio de Justicia y Derechos Humanos.

${ }^{23}$ Ley 25.831/04 "Régimen de Libre Acceso a la Información Pública Ambiental", 6 de enero de 2004. Buenos Aires, Argentina: Ministerio de Justicia y Derechos Humanos.

${ }^{24} \mathrm{La}$ jurisprudencia de la CSJN ha marcado el derrotero a seguir en casos señalados. Véase: CSJN, 26 de marzo del 2014, "CIPPEC c/ EN - Ministerio de Desarrollo Social - Dto. 1172/03 s/ amparo Ley 16.986”; CSJN, 10/11/2015, "Giustiniani Rubén Héctor c/ YPF S.A. s/ amparo por mora”; CSJN, 04 de diciembre de 2012, "Asociación Derechos Civiles vs. Estado Nacional - PAMI (Decr. 1172/2003) s/ amparo Ley 16.986"; CSJN, 12/08/2008, "Asociación Ecológica Social de Pesca, Caza y Náutica v. Provincia de Buenos Aires y otros s/ daños y perjuicios”; CSJN, 20/06/2006, "Mendoza, Beatriz Silvia y otros c/ Estado Nacional y otros s/ daños y perjuicios (daños derivados de la contaminación ambiental del Río Matanza-Riachuelo)”.

${ }^{25}$ La jurisprudencia internacional exhibe un fallo muy relevante y pertinente: "Claude Reyes y otros vs. Chile" (2006), con sentencia de la Corte IDH, en el que el derecho de acceso a la información fue derivado del derecho a la libertad de pensamiento y de expresión (art. 13, Convención Americana de Derechos Humanos, 1969). Los hechos de este precedente son muy ilustrativos, ya que la información a la que se pretendía acceder era relativa a un proyecto de explotación ambiental, y cobran especial relevancia por cuanto la mencionada convención ostenta jerarquía constitucional (art. 75, inciso 22, Constitución de la Nación Argentina, 1994).
} 
Es incuestionable que cada paradigma regulatorio elabora sus propios dispositivos y por ello los casos emplazados en las zonas grises resultan ambivalentes. En el caso analizado, los fines que se pretenden alcanzar a través del secreto y la técnica de ocultación deliberada que este representa, tienen que ver con los acuerdos logrados por el sistema de actores intervinientes, en cuya constelación se hallan el SPT y el Estado -actuando como sujeto de derecho privado.

Según nuestro criterio, el fundamento que explica que los RGP procuren mantener en secreto algunas modalidades de su forma de operar da cuenta de que el contenido de dicho secreto integra la propiedad privada (de sus inversiones). De modo que mientras el secreto en los RGP es funcional a la protección de la propiedad privada (transnacional), para la órbita del derecho público la accesibilidad a la información es afín al ejercicio de instancias de control político y democrático.

El análisis de la dimensión institucional del secreto se enriquece si entendemos que el acceso a la esfera o arena pública -que garantiza, por un lado, una expresión efectiva de las personas y, por otro, el ejercicio de la democracia- hace viable la protección efectiva de los derechos humanos afectados por la opacidad de los acuerdos entre el SPT y los Estados.

En contraste con la dimensión institucional del secreto, las arenas públicas también ostentan una dimensión institucional, otorgada por la creación democrática de procedimientos mediante los cuales, los afectados por normas y decisiones políticas pueden influir en su formulación, estipulación y adopción (Benhabib, 1992: 87). Esto permitiría suponer que existen múltiples espacios o arenas públicas, que surgen en las sociedades modernas en torno a temas controvertidos de interés general. El contrato y su no accesibilidad convenida, acabó siendo objeto de publicización a través de su judicialización, conduciendo esta a la politización de los términos del acuerdo. El conflicto, por su carácter secreto y la ulterior definición de su contenido como público (luttes définitionnelles), puede ser leído como una expropiación de un espacio de confinamiento en favor de una arena pública (appropriations des problèmes).

Como se pudo observar, la publicización se realizó a través de mecanismos legales que trazaron canales de acceso entre estos campos legales y expropiaron el conflicto en favor de la arena pública. ${ }^{26}$ Cefaï (2002: 73;

${ }^{26}$ La noción de "arena pública" es un concepto analítico elaborado por Cefaï (2002), que permite explorar procesos relativos a causas públicas en los que interviene un auditorio variopinto de actores y poderes públicos que moldean la cosa pública. Para la sociología americana, la "arena social es [...] un teatro de acciones conjuntas, coordinadas y concertadas, y por lo tanto teatro de competiciones, de conflictos y de controversias, donde los individuos y los colectivos se encuentran alrededor de cuestiones compartidas, arreglan situaciones problemáticas, elaboran programas de acciones, se enfrentan en estrategias de interés, se comprometen en transacciones de todo tipo" (ibidem: 70-71). 
traducción de la autora) la ha definido como una "escena donde, ante los espectadores, se enfrentan los pretendientes a la 'propiedad' (ownership) de problemas públicos. Esta metáfora de la 'propiedad' incluye caracteres de control, de exclusividad y de transferabilidad", que son predicables en el abordaje del secreto. Sin embargo, quien formuló primeramente esta cuestión fue el sociólogo alemán Jürgen Habermas. En el concepto habermasiano de esfera pública se institucionalizaron un conjunto de intereses, la oposición entre Estado y sociedad, así como las prácticas del discurso racional crítico sobre asuntos políticos (Calhoun, 1992: 9), pero teniendo como precondición social el desarrollo de mercados de capital (ibidem: 15). Es decir, el desarrollo del capitalismo contribuyó sustancialmente a la configuración de la esfera pública. Este antecedente en el surgimiento de la esfera pública permite comprender que exista una fuerte tensión entre lo público y lo privado, entre esferas económicas y jurídico-políticas. Esta misma tensión se tradujo en el campo legal a través de la dicotomía entre lo público y lo privado que paulatinamente ha venido desdibujándose. La consagración legal de los mecanismos de acceso a la información pública, cuya técnica ha sido importada del régimen de los DD. HH., ha permitido ocultar su opacidad. Esto representa un punto de inflexión en el régimen que institucionaliza el secreto, confiscando el objeto de su regulación (la información) de una esfera de opacidad y trasladándolo a la arena pública $^{27}$ de los DD. HH., donde esta deviene en un bien público y social, soporte de los derechos fundamentales.

\section{A modo de cierre}

Como contracara de la dimensión institucional del secreto, se plantea el problema del acceso a la información pública. La dimensión institucional del secreto se pone de manifiesto no solo en la interface de campos legales, sino también en las prácticas y arreglos de los actores públicos y privados, y en las instituciones y reglas legales que le ofrecen a las relaciones jurídicas privadas (comerciales, financieras e industriales) una matriz opaca en la que resguardarse, lejos del control de las instituciones democráticas. Esto se constata incluso en los casos en que el Estado es el que se vincula con actores del SPT y sobre esto hemos centrado nuestro análisis.

El estudio de caso aquí abordado puso en evidencia un punto de tensión álgido entre un régimen legal de corte privatista y global, para el cual la

\footnotetext{
${ }^{27}$ Aunque aquí el concepto de "arena social" se haya tomado de la caja de herramientas de la sociología de las movilizaciones colectivas, el análisis de los procesos de institucionalización en materia de DD. HH. guarda muchas semejanzas -por su conexión con la vida política de los Estados y las comunidades- que habilitan el uso de esta categoría.
} 
información es confidencial, frente a las reglas de un sistema nacional e internacional que comprenden a la información como un bien público y colectivo sobre el que descansan los derechos fundamentales. El contraste de las lógicas de cada uno de estos órdenes normativos es indiscutible. No es una cuestión nimia si se repara en los resultados a los que conducen uno y otro sistema legal. Así, por ejemplo, el juego de normas jurídicas del RGP aplicable al caso habría confiscado esta información, obstando el ejercicio de DD. HH. Puesto en estos términos, las luchas por la definición de los problemas (luttes définitionnelles) no son lineales, ni intrascendentes.

En este sentido, como señalan Gilbert y Henry (2012: 42), se pueden seguir otras rutas para imponer definiciones de problemas, especialmente aquellas que permiten influir directamente sobre la delimitación de competencias y sobre el conjunto de procedimientos legales y administrativos involucrados. De este modo, la estrategia de judicializar el conflicto no fue sino una medida de publicización y expropiación en favor de la arena pública.

Sin embargo, esto fue viable no solo por su judicialización, sino en gran medida por la expansión de los dispositivos legales de los DD. HH., que permitieron flexibilizar ad hoc las reglas jurídicas de institucionalización del secreto.

En sintonía con el sesgo crítico adoptado, resta señalar una última apreciación. En este orden, el vínculo y los términos de los acuerdos entre los sujetos del corporativismo transnacional y el Estado no sólo han llevado a cabo una privatización de las funciones de regulación por parte del Estado, sino que se ha producido un desplazamiento de las funciones de control democrático, ya que la información -bien colectivo y público sustrato del ejercicio de derechos fundamentales- ha sido confiscada en favor de los RGP.

Es indiscutible que la opacidad del derecho es funcional al mantenimiento de relaciones jurídicas globales y privadas. La función de la inaccesibilidad de estos acuerdos radica en opacarse ante los mecanismos de control político e institucional de los Estados, así como de la sociedad civil. La tensión en la interface entre estos campos legales, lejos de diluirse, probablemente persista por el desarrollo expansivo de los RGP; no obstante, la estrategia de redefinir secciones de estos regímenes como elementos constitutivos de la arena pública pone de manifiesto un sólido potencial en términos políticos y legales.

Revisado por José Morales 


\section{Referencias bibliográficas}

AAVV (2014), 20 Mitos y realidades del fracking, colección Chico Mendes. Buenos Aires: El Colectivo.

Abramovich, Víctor (2015), "Poderes regulatorios estatales en el Pluralismo Jurídico Global”, Revista de Derecho Público, IV(11), 3-33.

Abramovich, Víctor; Courtis, Christian (2000), "El acceso a la información como derecho”, Anuario de Derecho a la Comunicación, I(I), 223-256. Buenos Aires: Siglo XXI.

Asociación por los Derechos Civiles (2015), Informe "El (des)control democrático de los organismos de inteligencia en Argentina”. Buenos Aires. Consultado el 02.06.2019, en https://adcdigital.org.ar/wp-content/uploads/2016/01/El-des-controldemocratico.pdf.

Azuela, Antonio (2006), Visionarios y pragmáticos: una aproximación sociológica al derecho ambiental. México, D.F.: Universidad Nacional Autónoma de México, Instituto de Investigaciones Sociales.

Basterra, Marcela I. (2014), "Los límites al ejercicio del derecho de acceso a la Información Pública. El caso 'Chevron'”, Revista de Derecho Ambiental de la Universidad de Palermo, III(2), 121-168.

Benhabib, Seyla (1992), "Models of Public Space: Hannah Arendt, the Liberal Tradition and Jürgen Habermas”, in Craig Calhoun (comp.), Habermas and the Public Sphere. Cambridge, MA: MIT Press, 73-98.

Berman, Paul Schiff (2012), Global Legal Pluralism: A Jurisprudence of Law Beyond Borders. New York: Cambridge University Press.

Bourdieu, Pierre; Teubner, Gunther (2000), La fuerza del derecho. Bogotá: Siglo del Hombre Editores, Facultad de Derecho de la Universidad de los Andes, Ediciones Uniandes, Instituto Pensar. Estudio preliminar y traducción de Carlos Morales de Setién Ravina.

Calhoun, Craig (comp.) (1992), "Introduction: Habermas and the Public Sphere”, in Habermas and the Public Sphere. Cambridge, MA: MIT Press, 1-48.

Cárcova, Carlos María (1998), La opacidad del derecho. Madrid: Editorial Trotta.

Casa Rosada - Presidencia de la Nación (2012), “Anuncio del proyecto de ley de expropiación de YPF: discurso de la Presidenta de la Nación”, Casa Rosada, 16 de abril. Consultado el 16.04.2012, en https://www.casarosada.gob.ar/informacion/ archivo/25810-anuncio-del-proyecto-de-ley-de-expropiacion-de-ypf-discurso-dela-presidenta-de-la-nacion.

Cefaï, Daniel (2002), “Qu'est-ce qu'une arène publique? Quelques pistes pour une approche pragmatiste”, in Daniel Cefaï; Isaac Joseph (coords.), L'béritage du pragmatisme. Conflits d'urbanité et épreuves de civisme. La Tour d'Aigues: Éditions de l'Aube, 51-81.

Gilbert, Claude; Henry, Emmanuel (2012), "La définition des problèmes publics: entre publicité et discrétion”, Revue française de sociologie, 53(1), 35-59. 
Giraud, Claude (2005), Du secret, contribution à une sociologie de l'autorité et de l'engagement. Collection Logiques Sociales. Paris: Editions L'Harmattan.

Han, Byung-Chul (2013), La sociedad de la transparencia. Burzaco, Buenos Aires: Herder. Kuuskraa, Vello; Stevens, Scott; Leeuwen, Tyler Van; Moodhe, Keith (2011), World Shale Gas Resources: An Initial Assessment of 14 Regions outside the United States. Arlington, VA: Energy Information Administration/Office of Energy Analysis/ Department of Energy, IV-8.

Muir Watt, Horatia (2011), "Private International Law beyond the Schism", Transnational Legal Theory, 2(3), 347-428.

Muir Watt, Horatia (2016), "Conflicts of Laws Unbounded: The Case for a Legal-Pluralist Revival”, Transnational Legal Theory, 7(3), 313-353.

Pfersmann, Otto (2006), "Norme de secret, normes secrètes et État moderne", Cités, 26(2), 115-126. Consultado el 05.04.2017, en http://www.cairn.info/revue-cites2006-2-page-115.htm.

Saba, Roberto (2017), “Acceso a la información y Seguridad Nacional”, Revista Estudios en Derecho a la Información, 3, 99-110. Consultado el 12.04.2017, en http://www. palermo.edu/Archivos_content/2017/derecho/febrero/paper_acceso_info/Saba_ Acceso_informacion_y_seguridad_nacional.pdf.

Santos, Boaventura de Sousa (2003), Crítica de la razón indolente. Contra el desperdicio de la experiencia. Vol. I: Para un nuevo sentido común: la ciencia, el derecho y la política en la transición paradigmática. Bilbao: Editorial Desclée de Brouwer [orig. 2000].

Sassen, Saskia (2010), Territorio, autoridad y derechos. De los ensambles medievales a los ensambles globales. Buenos Aires: Katz. Traducción de María Victoria Rodil [orig. 2006].

Sassen, Saskia (2012), Una sociología de la globalización. Buenos Aires: Katz. Traducción de María Victoria Rodil [orig. 2007].

Simmel, Georg (2014), Sociología: estudios sobre las formas de socialización. México: Fondo de Cultura Económica. Traduccioón de José Pérez Bances [orig. 1908].

Teubner, Gunther (1998), "The Two Faces of Janus: Rethinking Legal Pluralism”, in Kaarlo Tuori; Zenon Bankowski; Jyrki Uusitalo (comps.), Law and Power: Critical and Socio-Legal Essays. Liverpool: Deborah Charles, 119-140.

Teubner, Gunther (2004), "Global Private Regimes: Neo-Spontaneous Law and Dual Constitution of Autonomous Sectors?”, in Karl-Heinz Ladeur (comp.), Public Governance in the Age of Globalization. Aldershot: Ashgate, 71-87. Consultado el 16.04.2017, en https://ssrn.com/abstract=894423.

Teubner, Gunther (2012), Constitutional Fragments: Societal Constitutionalism and Globalization. Oxford: Oxford University Press. 
Recibido: 23.06.2017

Aceptación comunicada: 01.02.2019

\section{Carolina Filippon}

Instituto de Humanidades y Ciencias Sociales del Litoral, Facultad de Ciencias Jurídicas y Sociales, Universidad Nacional del Litoral

Cándido Pujato n. ${ }^{\circ}$ 2751, 1. ${ }^{\circ}$ piso, ala este - CP 3000, Ciudad de Santa Fe, Provincia de Santa Fe,

Argentina

Contacto: carolina.filippon@gmail.com

ORCID: https://orcid.org/0000-0001-8736-9801

\section{Opacity in Global Agreements.} A Socio-Legal Approach about Secrecy in the Legal Field

In the field of private global regimes, arrangements and practices between actors in the transnational private sector and the State exhibit a level of opacity that has hampered the exercise of fundamental rights, such as access to public information. We consider it fundamental to explore this tension between private global regimes and the field of human rights via the study of the institutional and legal variables of secrecy to account for the functional nature of the opacity of the law and the processes of publicity that allowed for redefinition as a public problem in the legal field.

Keywords: human rights; information access; international contracts; right to information.

\section{Opacité dans les accords} internationaux. Une approche sociojuridique à propos du secret sur le plan juridique

Dans le domaine des régimes globaux privés, les arrangements et les pratiques entre les acteurs du secteur privé transnational et l'État présentent un niveau d'opacité qui a entravé l'exercice des droits fondamentaux, tels que l'accès à l'information publique. Cet article propose d'explorer cette tension entre les régimes globaux privés et le domaine des droits humains, par l'étude des variables institutionnelles et juridiques du secret, pour tenir compte de la nature fonctionnelle de l'opacité du droit et des processus de publicisation qui ont permis la redéfinition en tant que problème public dans le domaine juridique. Mots-clés: accès à l'information; contrats internationaux; droit à l'information; droits humains. 